\title{
ANÁLISE DOS PERSONAGENS BRASILEIROS DA FRANQUIA STREET FIGHTER - IDENTIDADE E REPRESENTAÇÃO NOS VIDEOGAMES
}

\author{
Analysis of Brazilian Characters from the Street Fighter Franchise - Identity \\ and Representation in Videogames
}

Análisis de Personajes Brasileños de la Franquicia Street Fighter - Identidad y Representación em los Videojuegos

Rafael Arrivabene

Professor do curso de Design de Jogos e Entretenimento Digital - UNIVALI

rafael.arrivabene@univali.br

José Roberto Cordeiro

Mestrando do curso de Pós-Graduação em Engenharia e Gestão do Conhecimento - UFSC

zerocordeiro@gmail.com

Richard Perassi

Professor do curso de Pós-Graduação em Engenharia e Gestão do Conhecimento - UFSC

richard.perassi@ufsc.br

\section{Resumo}

No contexto da pós-modernidade, a identidade individual é ativamente construída a partir de relações de afeto e consumo, como por exemplo, o consumo de mídia. Os jogos digitais possibilitam que jogadores expressem-se e sintam-se representados através de seus protagonistas controláveis. Através de uma análise semiótica peirceana de três personagens, $o$ presente trabalho propõe-se a investigar a evolução da representação do Brasil e do brasileiro na franquia japonesa Street Fighter ao longo dos 30 anos da série. Elucida ao final como cada um destes qualifica e simboliza o povo brasileiro a partir de diferentes características nacionais incutidas no imaginário estrangeiro.

Palavras-chave: Character design. Videogames. Semiótica.

\begin{abstract}
In the context of postmodernity, individual identity is actively constructed from relations of affection and consumption, such as media consumption. Digital games enable players to express themselves and feel represented through their controllable protagonists. Through a Peircean semiotic analysis of three characters, the present work proposes to investigate the evolution of Brazil and the Brazilian people representation in the Japanese franchise Street Fighter throughout the 30 years of the series. Elucidating at the end how each of these
\end{abstract}


qualifies and symbolizes the Brazilian people from different national characteristics instilled in the foreign imagination.

Key words: Character design. Video games. Semiotics

\section{Resumen}

En el contexto de la posmodernidad, la identidad individual se construye activamente a partir relaciones de afecto y consumo, como el consumo de media. Juegos digitales permiten a los jugadores a expresarse y sentirse representados a través de sus protagonistas controlables. A través del análisis semiótico peirceano de tres caracteres, el presente trabajo propone investigar la evolución de la representación del Brasil y los brasileños en la franquicia japonesa Street Fighter a lo largo de los 30 años de la serie. Elucidat al final cómo cada uno de estos califica y simboliza el pueblo brasileño a partir de diferentes características nacionales inculcados en la imaginación extranjera.

Palabras clave: Diseño de personajes. Videojuegos. Semiótica

\section{IDENTIDADE CULTURAL E PERSONAGENS DE JOGOS DIGITAIS.}

O conceito de identidade, a percepção de quem se é e o senso de pertencimento e identificação com outros indivíduos vem se tornando uma construção cada vez menos rígida e permeável. Autores como Bauman e Vecchi (2005) e Michel Maffesoli (2007) defendem que o que antes seguia uma pré determinação geopolítica, hereditária e hierárquica, agora se mostra mais flexível e opcional. Embora identidades nacionais e semelhantes se mantenham presentes por exigências externas ao indivíduo, outros níveis de identidade se fragmentam em um amplo espectro de possibilidades. Além das categorias tradicionais como religião, partidarismo, regionalismo e comunidade linguística, uma miríade de novas bandeiras e filiações surgem na pós-modernidade. Impulsionadas pela comunicação digital globalizada, as "tribos pós-modernas" (Maffesoli, 2007) se formam, então, não apenas por proximidade geográfica e de parentesco, mas também à distância, através da identificação afetiva, de pontos de vista e interesses compartilhados. A proximidade física da comunidade, que antes dava corpo para a cultura, perde força ante ao celular, que permite que o espírito se distancie (BAUMAN; VECCHI, 2005, p. 33)

Nesse sentido, mídia e cultura popular desempenham papéis importantes na configuração de interesses. Para o professor Terry Eagleton, da Universidade de Oxford, no capitalismo avançado a "Alta Cultura", clássica e espiritual, perde espaço para a cultura de massa, comercial, e neste embate surge a cultura como identidade individual ou de grupo (EAGLETON, 2015, p.106). Em um movimento de afirmação de identidade, os indivíduos se juntam em torno de seus hábitos de consumo cultural e causas comuns. Exemplos bem 
conhecidos são os grupos formados a partir do gosto musical como Metaleiros e Funkeiros. Já os Otakus são os aficionados por cultura e quadrinhos japoneses, enquanto Potterheads colecionam tudo o que for relacionado à obra de J. K. Rowling. Vigotsky defendia que os signos escolhidos para suscitar um determinado estado de emoções em uma obra de arte exprimem a realidade social que lhe dá origem. A arte é humana e vem da realidade que o indivíduo vê e reconhece (BARROCO; SUPERTI, 2014). Assim, livros, filmes, músicas e jogos ajudam a constituir uma imagem mental de si mesmo, de seus pares e dos outros. Um processo de ressignificação se estabelece, no qual essas diferentes linguagens expressivas e suas obras ajudam a convencionar novos simbolismos.

Com os jogos digitais não seria diferente. Pesquisador dos jogos na educação, Kurt Squire (2003) entende que as crianças e jovens não são apenas consumidores passivos, mas que estes trazem os jogos para seu contexto social, falando sobre eles nas escolas e em seus grupos familiares e de amigos, geralmente reapropriando e ressignificando os símbolos das obras. Estudo desenvolvido por Mary Ulicsak e Sue Cranmer identifica a importância dos jogos na formação da criança e o potencial dessa mídia para a união familiar (ULICSAK, CRANMER, 2010). As pesquisadoras identificam que os jogos mais fáceis para que todos os membros da família participem são os Massively Multiplayer Online Role Playing Games (MMORPGs). Esta categoria de jogos já havia sido analisada por Dickey (2007), que identificara como principais componentes motivacionais o ambiente narrativo e a possibilidade de personalização dos personagens jogáveis, que criam uma conexão emocional mais próxima entre estes e o jogador.

Para os pesquisadores de mídia e comunicação Hefner, Klimmt e Vorderer, a identificação individual em jogos digitais é diferente da que acontece em mídias como a literatura e o cinema. Por não serem interativas, nestas a identificação se dá pela empatia ou falta dela para com os personagens da trama. Já nos jogos digitais a interatividade permite que o indivíduo se "sinta como" ou tenha a "ilusão de ser" o personagem (HEFNER et al., 2007). Jogos digitais têm o poder de criar experiências e narrativas interativas onde o senso de participação e imersão é aumentado, reforçando assim a conexão entre o indivíduo e as escolhas e ações de seu avatar virtual.

Entretanto, há uma variedade de maneiras pelas quais os personagens são disponibilizados aos jogadores. Em MMORPGs como World of Warcraft (ENTERTAINMENT, 2004) os personagens são totalmente construídos pelo jogador, que pode, dependendo do jogo, decidir o gênero, raça, traços de aparência física, habilidades, 
profissão e diversas outras características deste. Nestes jogos o personagem não tem uma história anterior nem uma predestinação rígida. Personagens de MMORPGs são como um formulário em branco aguardando o preenchimento do jogador. Pode-se posicionar este tipo de avatar digital em um dos extremos do espectro formado pelas diferentes possibilidades de protagonistas que os jogos oferecem. No extremo oposto podemos observar os personagens totalmente predefinidos, analisados no artigo de Hefner, onde a narrativa do jogo é tão imperativa, que o jogador apenas assume um controle momentâneo de um personagem com personalidade e características próprias. Jogos como The Last of Us (DOG, 2013) utilizam muitos recursos do cinema, construindo narrativas e personagens complexos, de maneira que limita a decisão dos jogadores sobre seu papel naquela obra. Finalmente há os casos que se encontram no meio deste espectro, nos quais há maior ou menor pré-definição dos personagens por parte dos criadores e maior ou menor liberdade de escolha por parte do jogador. É neste ponto que se encontram principalmente os E-Sports e, dentre estes, jogos de luta como os da franquia Street Fighter.

Tabela 1 - Exemplos de predefinição de protagonistas em jogos digitais.

\begin{tabular}{|c|c|c|c|}
\hline Character Design & Baixa predefinição & Média predefinição & Alta predefinição \\
\hline $\begin{array}{l}\text { Opções de } \\
\text { Protagonista }\end{array}$ & $\begin{array}{l}\text { Avatar totalmente } \\
\text { customizável }\end{array}$ & $\begin{array}{l}\text { Opções entre } \\
\text { avatares não } \\
\text { customizáveis }\end{array}$ & $\begin{array}{l}\text { Avatar não } \\
\text { customizável. }\end{array}$ \\
\hline Exemplos & $\begin{array}{l}\text { World of Warcraft, } \\
\text { Dragon Age: } \\
\text { Inquisition }\end{array}$ & $\begin{array}{l}\text { Street Fighter, } \\
\text { Overwatch }\end{array}$ & $\begin{array}{l}\text { The Last of Us, } \\
\text { The Witcher } 3 .\end{array}$ \\
\hline
\end{tabular}

Fonte: Elaborado pelos autores.

Muitos jogos considerados como E-Sports na atualidade se baseiam na escolha e domínio de um personagem ou equipe de personagens disponíveis. Jogos como League of Legends (RIOT GAMES, 2009), oferecem aos jogadores dezenas de personagens para que esta escolha com qual jogar a cada partida. A narrativa não é o ponto focal destes jogos, embora esteja presente em segundo plano. Todos os personagens são apresentados com características estéticas e habilidades predefinidas, bem como algum histórico e motivação, que justificam por que o personagem se engaja na atividade simulada pelo jogo: geralmente um confronto com os outros personagens. Nestes tipos de jogos, a criação dos personagens, 
também chamada de Character Design, parece então se pautar principalmente em aspectos funcionais e estéticos. A adoção de um destes personagens é um processo importante no processo de identificação do jogador com o jogo. Uma vez que o jogador não interpretará um personagem predeterminado e tampouco tem liberdade para criar o seu próprio personagem, resta a ele escolher, dentre os vários personagens já criados, aqueles com os quais mais se identifica. Pode-se entender a escolha do personagem nestes jogos competitivos como um dos momentos de expressão pessoal do jogador dentro dos limites que o sistema estabelece. Este pode ser o motivo pelo qual novos jogos como Overwatch (BLIZZARD ENTERTAINMENT, 2016) têm adotado maior diversidade de biotipo, nacionalidade e mesmo orientação sexual em seu rol de personagens (MCWHERTOR, 2014). Assim surge o interesse em entender melhor o processo de significação que se estabelece a partir do Character Design e sua influência na identificação do público com estes jogos. Com base nisso, foi decidido para este trabalho analisar através da semiótica peirceana quais mensagens são expressas através do Character Design dos personagens brasileiros na popular franquia Street Fighter e como estas mensagens se modificaram ao longo dos 30 anos da série.

\section{CHARACTER DESIGN E A FRANQUIA STREET FIGHTER}

Grande parte da atratividade dos videogames está no fato de estes serem uma mídia interativa, que proporciona uma participação ativa do público na obra. Devido ao foco na interação, inicialmente os personagens dos jogos digitais eram desenvolvidos a partir de suas habilidades e funções dentro do sistema. Mas, segundo El-Nasr et al. (2009), os jogos atuais vêm dando mais importância para a função narrativa dos personagens e assim os traços psicológicos de suas personalidades começam a influenciar mais o Character Design. Isto tem por objetivo apresentar ao público personagens mais verossímeis, com quem se possa estabelecer maior identificação. Segundo os pesquisadores, o público espera que os personagens, independente da mídia pela qual se apresentam, tenham personalidades próprias, distintas e memoráveis e que se expressem através de suas ações, objetivos e mesmo em sua linguagem não-verbal, como a linguagem corporal.

Como observado no estudo, esta preocupação é mais recente e certamente não é tão aparente em personagens de videogames dos anos 80 como Ms. Pac-man (MIDWAY MANUFACTURING CO, 1981) ou os Super Mario Bros. (NINTENDO, 1985), porém 
começa a ser observada em Ryu, Ken e seus adversários no primeiro Street Fighter (CAPCOM, 1987). Além de apresentar maior definição gráfica, que permite aos jogadores identificarem melhor as características dos personagens, incluindo seus rostos e algumas expressões faciais, este jogo identifica a nacionalidade dos personagens, que por sua vez influencia nas características destes. Geki, por exemplo, é apresentado como um lutador do Japão; suas vestes são as de um ninja, e esta premissa narrativa justifica seus movimentos de luta característicos, como o lançamento de shuriken e bombas de fumaça. Em Street Fighter, uma característica narrativa - a nacionalidade - é um ponto de partida para a construção do personagem, influenciando sua aparência e suas habilidades.

Após o sucesso do jogo, o segundo título do que veio a ser uma série duradoura foi lançado em 1991, com o nome de Street Fighter II: The World Warrior (CAPCOM, 1991). Ryu e Ken retornam para mais uma série de duelos ao redor do mundo, mas desta vez o jogador pode escolher também entre outros seis lutadores inéditos, além destes dois originais. Se antes os jogadores tinham de optar em jogar com o personagem japonês ou com o americano, agora, além de outras opções de ambos os países, ainda há lutadores vindos da China, União Soviética, Índia e até mesmo do Brasil. Neste título também foi apresentada a primeira lutadora, a chinesa Chun-li, e também o primeiro não-humano, o brasileiro Blanka, indicando a variedade de tipos de personagens que a série agruparia no futuro.

O jogo foi um sucesso em muitos países, o que levou a desenvolvedora Capcom a investir em novos títulos da marca, que se tornou uma de suas séries mais rentáveis, com 38 milhões de unidades vendidas (CAPCOM, 2016). Mais do que apenas jogos de videogame, Street Fighter se transformou em uma marca ou franquia multimídia, que conta com filmes, animações, histórias em quadrinhos, bonecos, jogos de tabuleiro, entre outros produtos. Sendo também uma das modalidades do campeonato EVO, considerado o maior campeonato de videogames de luta (WALLBRIDGE, 2009) e também do Capcom Cup, torneio internacional organizado e patrocinado pela desenvolvedora dos jogos. Hoje, mais de 30 anos após sua estreia, a série acumula cerca de 60 personagens, dos quais três são brasileiros. Estes serão, portanto, objeto de análise deste estudo com o objetivo de identificar o simbolismo empregado na construção de tais personagens.

\section{SEMIÓTICA APLICADA À CRIAÇÃo DE PERSONAGENS DE VIDEOGAMES}


Santaella (2012, p. 170) separa as imagens em três modalidades: imagens em si mesmas, cujo significado é limitado à sua própria forma; imagens figurativas, que se assemelham a algo real ou imaginário, e imagens simbólicas, que se apresentam como figuras reconhecíveis mas trazem significados além do que pode ser visto, codificados em elementos visuais e compositivos que carregam conceitos mais profundos do que uma breve descrição da imagem consegue explicitar. Os personagens de Street Fighter se encaixam nesta última categoria, afirmando suas identidades através de aparência física, roupas, acessórios, gestos e falas.

A semiótica peirceana foi escolhida como ferramenta de análise para este estudo por fornecer instrumental teórico adequado não só para interpretação de imagens, mas também os diferentes sinais e linguagens pelo qual o conceito do personagem é comunicado ao jogador. Para Peirce, um signo ou representamen é "alguma coisa que significa algo para alguém" (SANTAELLA, 1995, p.22), sendo um intermediário entre um objeto - o qual pode ser algo sólido e real ou apenas uma ideia ou conceito - e um suposto receptor que, em contato com o signo, cria um interpretante em sua mente, o qual é definido pelas características perceptíveis do signo. Assim, neste estudo tratamos os personagens como signos de brasilidade, carregando consigo características que denotam o "tipo" de Brasil que os produtores do jogo querem transmitir aos jogadores.

Salienta-se que o personagem multimídia só pode ser compreendido em sua totalidade através da conjunção de suas expressões em cada mídia que se apresenta. Francisco e Garone (2013) argumentam que um personagem é uma pessoa ou criatura fictícia idealizada em uma obra, e que a área de Character Design deve se preocupar com pelo menos estas características: expressão corporal, apresentação visual, psicológico e indumentária. Frosi e Steffen (2015) citam que os personagens sempre possuem a combinação das dimensões mentais e físicas, e que nos jogos digitais a dimensão física prevalece, uma vez que o jogador pensará pelos personagens na maior parte do tempo. Citando o game designer Jesse Schell, indicam que o processo de criação de um personagem tem de considerar sua função, seu psicológico, expressões faciais, voz e ainda outras características como status e círculo social deste. Portanto defende-se que a análise de um personagem ficcional animado, além de suas formas e cores perceptíveis, deve também interpretar as características de seus movimentos. Se este fala ou emite sons, deve-se estudar as características de sua sonorização e o conteúdo e forma de sua linguagem verbal. É importante notar que alguns autores, como as professoras universitárias Maagerø e Østbye (2016), linguista e pedagoga, respectivamente, sugerem que 
a ferramenta mais adequada para análise de um personagem seria a semiótica social multimodal, proposta por Gunther Kress (2010). Esta teoria entende que a construção de significado não é um processo passivo, e sim ativo, sempre contextual e que se opera em muitos meios simultaneamente. A teoria se aprofunda mais na análise do discurso do que o pretendido neste momento, mas parece ser um caminho a ser estudado.

Segundo a teoria peirceana, pode-se analisar um signo a partir de três categorias fenomenológicas, chamadas de Primeiridade, Secundidade e Terceiridade, as quais referem-se respectivamente às três propriedades formais do signo: sua qualidade, sua existência e seu caráter de lei (SANTAELLA, 2002 p.12). A Primeiridade é o momento da primeira impressão que se tem de um signo, as sensações que podem ser sentidas no corpo e pela mente, praticamente desprovidas de significados. Na Secundidade percebe-se a existência de uma origem e causa para tais sensações, ocorrendo uma primeira interpretação do signo e através das relações que suas características imediatas possibilitam. $\mathrm{Na}$ Terceiridade associa-se os aspectos sensíveis da primeira com a constatação de sua origem, interpretando-os de acordo com regras estabelecidas a partir da vivência e convenções culturais do intérprete, criando-se assim significados variados e mais complexos em um processo contínuo. O signo pode então ser analisado a partir de cada uma dessas categorias, em combinação com os três componentes que criam seu fenômeno: o representâmen, aquilo que de fato é percebido; o objeto, que é aquilo que este primeiro representa; e o interpretante, que é o efeito representativo causado. A partir desta combinação, os signos podem então ser classificados de acordo com sua propriedade formal prioritária, pelo modo como se relacionam com o objeto a que se referem e pelo nível de interpretação que estão aptos a gerar. Defende-se aqui que tal estrutura de análise permite o estudo de diferentes mídias, sendo, portanto, adequada para o estudo.

Tabela 1 - Categorias fenomenológicas e tricotomias peirceanas.

Representâmen $\quad$ Objeto Interpretante

\begin{tabular}{llll}
\hline Primeiridade & Quali-signo & Rema
\end{tabular}

\begin{tabular}{|l|l|l|}
\hline Secundidade & Sin-signo & Índice
\end{tabular}




\section{$\begin{array}{lll}\text { Terceiridade } & \text { Legi-signo } & \text { Argumento }\end{array}$}

Fonte: Elaborado pelos autores a partir de Santaella (2002).

Em concordância, estudos sobre semiótica aplicada ao Character Design sustentam que a análise de personagens pode se beneficiar desta estrutura, a partir da primeira e segunda tricotomia, a propriedade formal do signo e sua relação com o objeto representado (ALMEIDA et al, 2009). Assim o personagem analisado enquanto quali-signo icônico, é principalmente um signo cromático, que permite identificar as interpretações e convenções possíveis a partir de suas formas e cores. Enquanto sin-signo indicial, o personagem é interpretado por seus elementos singulares, por sua postura e indumentária, mesmo que estas também sejam representações icônicas destes elementos. Por fim, como legi-signo simbólico, o personagem se constrói como conjunção das convenções expressas pelas diferentes representações icônicas que o compõem. Este método de análise através da primeira e segunda tricotomia permite que na primeiridade sejam feitas inferências sobre as qualidades abstratas do signo e prever associações que estão aptas a produzir; na secundidade a manipulação das cores e formas criam um contexto singular que caracterizam a existência do personagem, remetendo iconicamente a outros signos que o compõem; na terceiridade, o signo já é convencional e simbólico, e os elementos de sua composição remetem a padrões e tipos socialmente estabelecidos, intensificando seu poder representativo (GÜNTZEL et al. 2011). O presente artigo pretende seguir esta linha e analisar o potencial comunicativo dos três personagens brasileiros da franquia Street Fighter, segundo suas primeira e segunda tricotomias.

Serão analisados a seguir cada personagem individualmente, em ordem cronológica de introdução na série, e de acordo com os três momentos da semiose peirceana. Para tanto as amostras observadas não são uma imagem estática. Tal como Almeida et al. (2009) analisam diversas versões da personagem da marca Leite Moça, também aqui é necessário interpretar o personagem como um signo que se estabelece através de diferentes instâncias de representação. Os personagens se apresentam ao público através de sua imagem animada e seus sons durante o jogo, mas também em imagens estáticas, ou mesmo nas outras mídias da franquia, como HQs e filmes animados. Em cada momento o personagem é representado por artistas diferentes, através de técnicas gráficas diferentes, mas suas características distintivas e 
singulares permanecem através das representações. A fim de conseguir capturar a essência de cada personagem e seu potencial simbólico, cada um será analisado através de sua aparência visual como apresentada nas imagens, movimentos, falas e sons e seus respectivos cenários observados durante jogo no qual figuram.

Figura 1 - Personagem Blanka representado em diferentes mídias oficiais da franquia
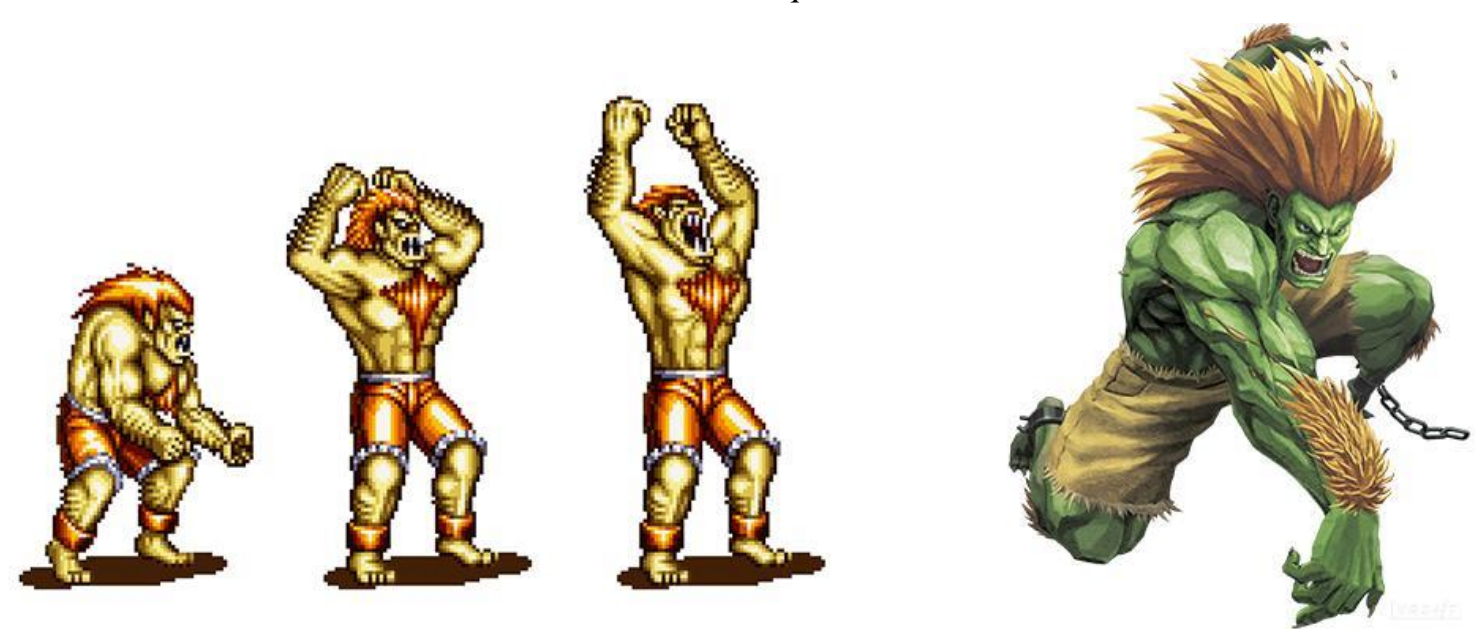

Sequência de movimentos no jogo.

Ilustração em material de divulgação.

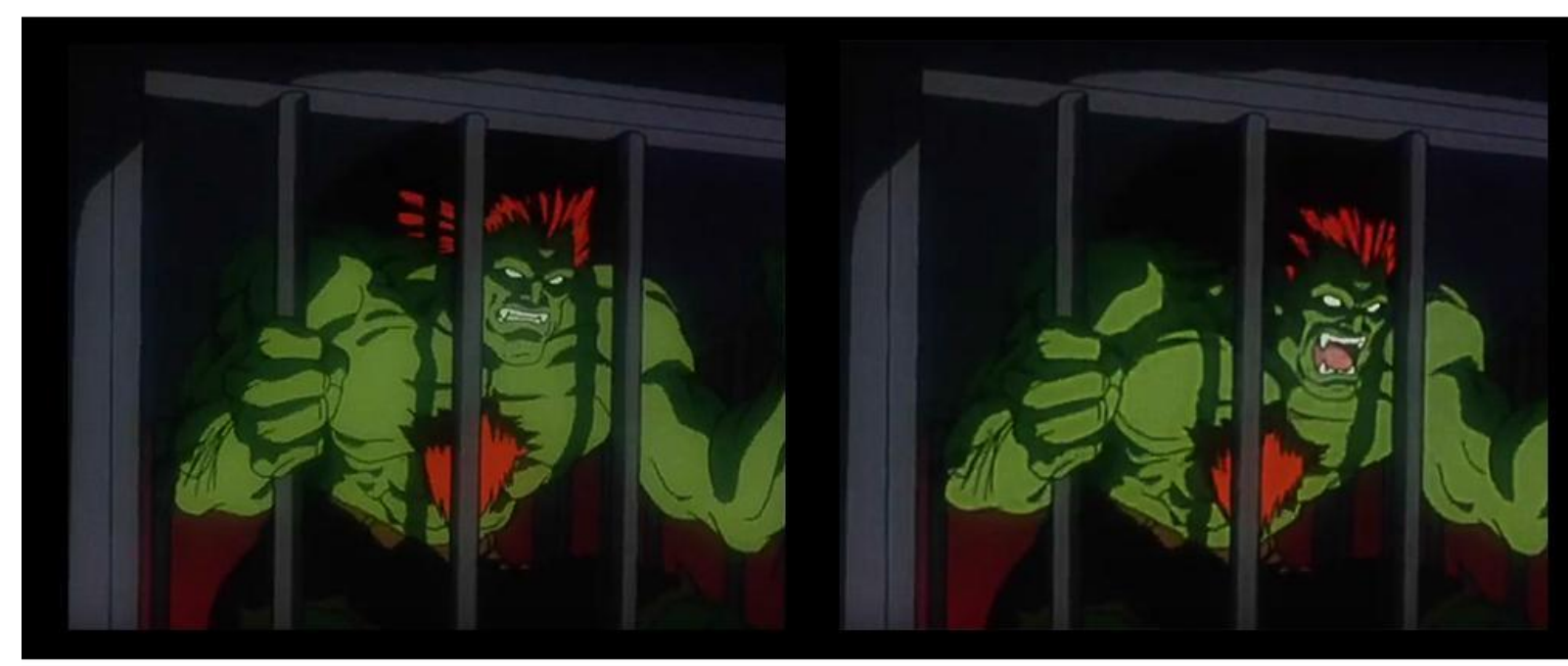

Sequência de movimentos no desenho animado.

Fonte: Elaborado pelos autores com imagens de http://www.fightersgeneration.com/characters/blanka.html

\subsection{Blanka - 1991}

Este foi tanto o primeiro personagem brasileiro da série Street Fighter, como também um dos primeiros personagens brasileiros na história dos videogames. Sua aparência, hoje emblemática, foi sempre motivo de controvérsia. A série de reportagens sobre a cultura gamer 
no Brasil, chamada Paralelos, captura alguns depoimentos sobre este fenômeno. O jornalista Pablo Miyazawa relembra que "um dos grandes sonhos de quem jogava videogame quando criança (...) era se ver representado no game. Eu me lembro - diz ele - da revolução do Blanka! (...) Um monstro, mas era brasileiro!” O contraponto vem na voz do rapper Emicida: “O Blanka representação brasileira? Como é que você vai sentir orgulho do Blanka?"(REDBULL, 2016, em 4min 33s). Estas frases e o resto dos depoimentos que se seguem são sintomáticos do sentimento misto gerado pelo personagem. A análise a seguir pode ajudar a esclarecer seus motivos.

No primeiro momento da semiose, o personagem se apresenta ao jogador como um conjunto de sinais primários, ainda passíveis de maior interpretação. Nota-se imediatamente a predominância da cor verde seguida por um tom ocre alaranjado. Ambas as cores de um tom terroso e quente, saturado, podendo levar à sensação de lama úmida e folhagens. Estas cores compõem a maior parte da figura bípede, porém animalesca. As cores e formas combinadas apresentam qualidades icônicas que são prontamente interpretadas como os elementos que compõem o personagem. Assim, o observador percebe que além de possuir a pele verde e os longos cabelos e pelos alaranjados, Blanka possui garras e presas pontiagudas. Seu corpo extremamente musculoso está sempre exposto, pois a única peça de indumentária com que o personagem é retratado é um calção rasgado, como se fosse gasto ou pequeno demais para seu corpo. A inumanidade de Blanka se transmite também através de seus movimentos brutos e fortes, mais próximos de um símio do que de um hominídeo, e também pelos sons que produz, parecidos com urros e uivos, poucas vezes articulando palavras. Quando é oponente ao jogador, a luta contra Blanka acontece sobre palafitas às margens de um grande rio, onde pescadores exibem um peixe enorme e uma cobra igualmente grande se enrola em uma árvore. Em algumas de suas representações mais detalhadas, percebe-se melhor os grilhões de metal em seus tornozelos, indicando que em algum momento a criatura já esteve presa. Blanka, é portanto, em primeira instância, um quali-signo icônico de monstruosidade, tal qual representada em obras de ficção.

Ao interpretar as qualidades imediatas transmitidas nas diferentes representações do personagem Blanka, percebe-se que estas remetem a uma ideia de natureza primitiva, que pode ser misteriosa, assustadora e feroz. A predominância da cor verde ajuda a associá-lo à bandeira brasileira, mas também à natureza e à floresta amazônica, que se afirma no jogo - por convenção - ser onde o personagem vive. A postura e o gestual de Blanka remetem a um gorila ou macaco, também simbolizados por sua abundância de pelos. Os 
grilhões quebrados em conjunto com a pouca roupa e rasgada ajudam a simbolizar uma força que não pode ser contida, ou que não se adequa à civilidade. Também as falas do personagem - geralmente apresentada através de textos no jogo - remetem a um ser ainda em desenvolvimento intelectual e emocional. Neste aspecto, Blanka é geralmente retratado falando sobre comida, em especial bananas, sobre sua mãe, ou emitindo grunhidos e urros, tal como na sonorização do personagem. Dentre os poucos elementos que podem ser interpretados, por convenção e hábito, como tipicamente brasileiros, estão alguns poucos golpes que se assemelham aos da capoeira. Entretanto, em sua maioria, os movimentos de Blanka são mais próprios de uma fera, incluindo mordidas e arranhões, executados de forma que transparecem uma força bruta, quase sem controle. Em suma, Blanka é um símbolo do Brasil Selvagem. Uma visão do Brasil como terra ainda selvagem onde misteriosos animais e criaturas se escondem na floresta, sem contato com a civilização.

Figura 2 - Personagem Sean representado em diversas mídias oficiais.
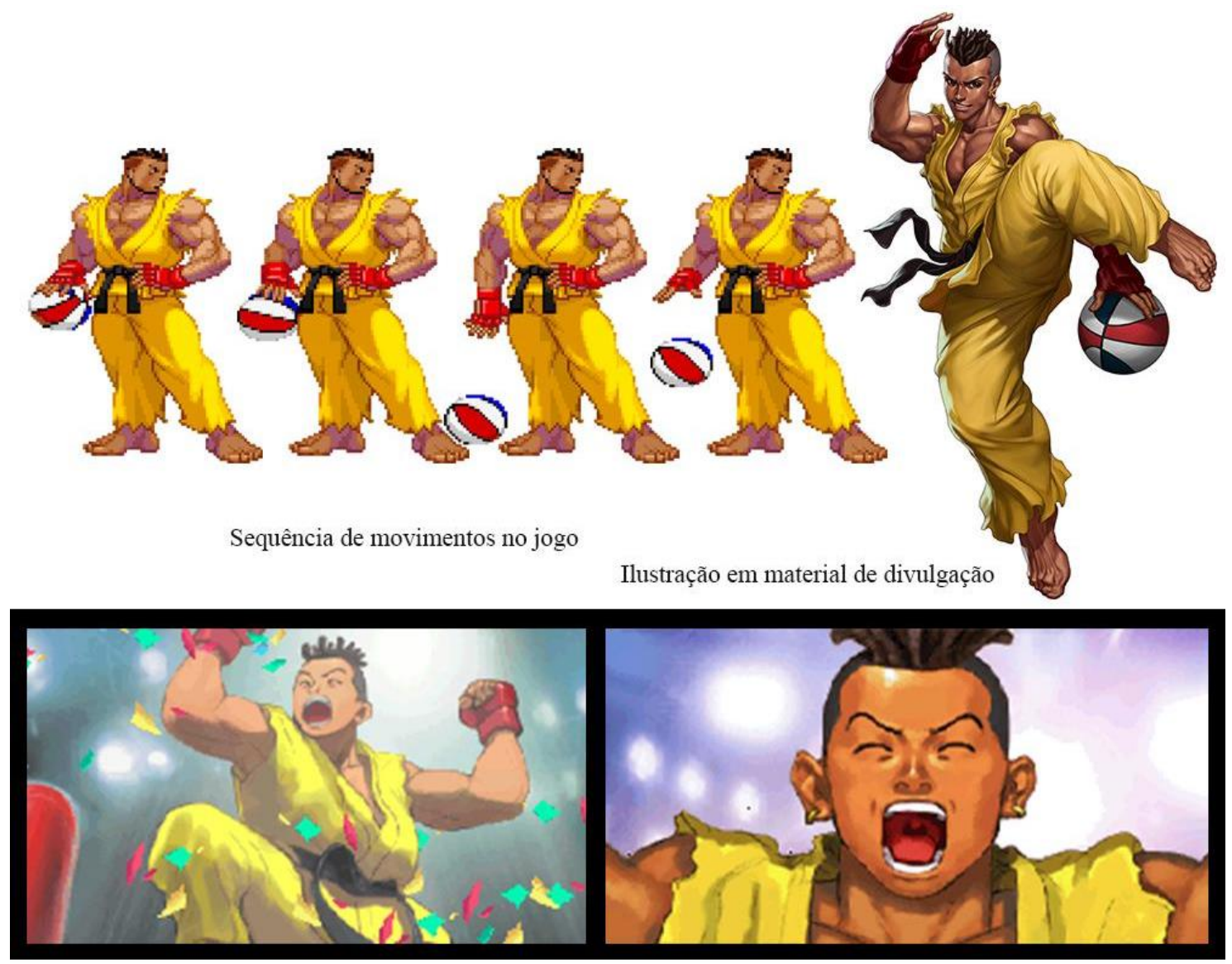

Sequência de imagens no fim do jogo

Fonte: Elaborado pelos autores com imagens de http://www.fightersgeneration.com/characters3/sean.html 


\subsection{Sean Matsuda - 1997}

Adicionado ao elenco da série no jogo Street Fighter III (CAPCOM, 1997), Sean não retornou como personagem jogável em nenhum dos títulos posteriores da empresa, diferentemente de seu antecessor e de outros que foram introduzidos na mesma época. Talvez este seja um dos motivos pelos quais o personagem, aparentemente, não tenha feito muito sucesso entre os brasileiros da mesma forma como Blanka fez, a despeito de sua polêmica aparência. Ainda assim, a análise de Sean enquanto signo de um processo de comunicação pode ajudar a entender outros fatores para seu baixo apelo.

Sean se apresenta, em primeiridade, com qualidades muito recorrentes na franquia Street Fighter. Sua silhueta compartilha em grande parte dos mesmos contornos e formas de outros personagens como Ryu, Ken, Dan e Akuma, os quais são todos imediatamente diferenciados pelas cores predominantes de seus quimonos, que compõem quase a totalidade da cor de cada personagem. Neste ponto, Sean é identificado pela predominância de um amarelo saturado. Esta cor contrasta-se pouco com o marrom escuro utilizado para indicar sua pele morena. Interpretando os significados das manchas de cor que o compõem, percebe-se que além do quimono, sua indumentária conta ainda com luvas vermelhas que deixam os dedos descobertos, típica das artes marciais mistas (MMA) e que sua pele indica uma origem ou ascendência africana. Seu corpo é forte e musculoso durante a ação do jogo, mas quando representado nas ilustrações estáticas complementares que são exibidas na tela de seleção de personagem aparece como visivelmente mais magro e menor em comparação aos outros lutadores. Seu rosto é magro, de traços suaves e aparência jovem, que se reforça no sorriso sempre presente. Usa um pequeno brinco nas orelhas e um corte de cabelo, raspado dos lados, mas com tranças na parte superior. A soma de suas características, especialmente quando observadas no contexto do elenco de personagens do jogo, faz com que Sean se mostre como um quali-signo icônico de juventude. Uma jovialidade adolescente, energética e irreverente.

Ao estender a observação ao nível do simbólico e observar as associações convencionais possíveis a partir dos sinais que o personagem emite, algumas dissonâncias ocorrem. Sean é definido a priori como brasileiro, sempre retratado no porto de Santos ou ruas de São Paulo; porém, é constantemente representado com uma bola de basquete vermelha, branca e azul, um símbolo que, apesar de reforçar sua característica esportiva, é também duplamente americano. Seus movimentos de luta são funcionalmente os mesmos dos outros personagens de sua categoria, que praticam um estilo japonês fictício. Mas apesar das 
semelhanças, os golpes de Sean são visivelmente diferentes por serem mais cômicos, exagerados e até incompletos em comparação com os demais. Isso pode ser justificado através das falas do personagem, onde este se revela um estudante de artes marciais esforçado e impetuoso. Novamente encontra-se a juventude de Sean como a característica norteadora de seu design. Conclui-se que Sean tem poucos elementos tipicamente relacionados ao Brasil. Entretanto, a imagem de um jovem de pele escura, esportista de qualidade e com atitude despojada pode ser associada a uma quantidade de talentos do futebol reconhecidos internacionalmente, como Pelé, Romário, Ronaldo, Ronaldinho Gaúcho, Robinho e outros. Assim como estes, Sean é um símbolo do Brasil Moleque, um jovem talento.

Figura 3 - Personagem Laura no jogo Street Fighter $V$
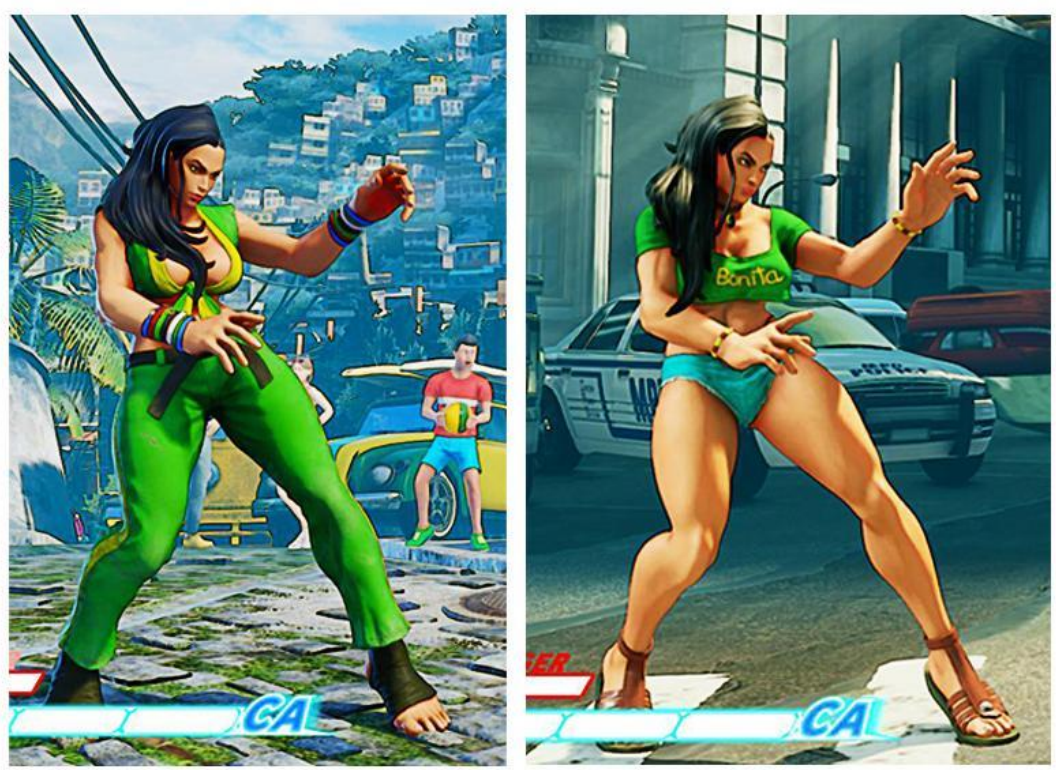

Roupa principal e roupa do modo Story

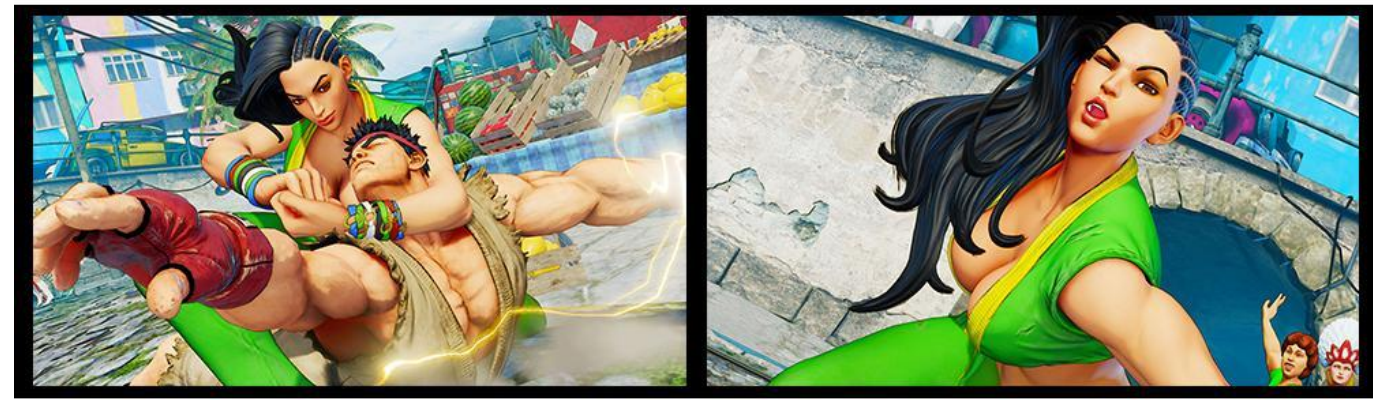

Detalhe das animações durante o jogo.

Fonte: Elaborado pelos autores com imagens de http://streetfighter.com/characters/laura/

\subsection{Laura Matsuda - 2015}


Quase 20 anos após Sean, Laura, sua irmã mais velha, foi apresentada ao público durante a Brasil Game Show pelo próprio produtor da série, Ono Yoshinori. O produtor vestia uma fantasia de Blanka, e revelou no palco principal uma estátua em tamanho real da personagem. Laura integra a lista de lutadores de Street Fighter V (CAPCOM, 2015), título mais recente da série, que possui algumas diferenças consideráveis em relação aos anteriores, e que são relevantes para essa análise. Antes os personagens eram representados por ilustrações em pixel art animadas quadro-a-quadro, mas agora os personagens são tridimensionais, o que permite que sua aparência seja modificada, inclusive com a adição e subtração de elementos, sem que haja o retrabalho da animação. O resultado é que agora os personagens, além de sua roupa padrão, possuem ainda uma coleção de roupas secundárias disponíveis para os jogadores. Embora cada variação ajude a compor a personagem, a análise de todas estas roupas adicionais seria inviável. Opta-se aqui por analisar apenas a roupa padrão e a primeira variação, que aparecem durante o modo Story do jogo, onde o jogador controla Laura e observa sua trajetória através de histórias em quadrinhos entre uma luta e outra.

O Brasil representado por Laura apresenta-se na silhueta de uma jovem magra, mas atlética e curvilínea. Sua pele é clara e seus cabelos negros, dos quais uma parte é solta, lisa e alongada enquanto a outra possui tranças rentes ao couro cabeludo. Esta combinação traz uma sensação latina. Sua roupa principal é composta de uma camisa decotada sem mangas e uma calça comprida que, ao mesmo tempo que não é muito justa, também não deixa de exibir seu corpo curvilíneo. As duas peças trazem a predominância do verde com detalhes em amarelo e preto. Estas dão uma sensação de roupas esportivas, reforçada pelo uso de tornozeleiras e luvas, mas com um toque feminino, acentuado pelo nó da camisa, abaixo do busto, visível através de um decote largo. O tom de verde utilizado é claro, brilhante, sugerindo leveza. No traje secundário, Laura se apresenta vestindo sandálias de praia, um top verde com a palavra "bonita" em amarelo, acompanhado por um mini shorts azul-claros, ambos curtos, transmitindo uma sensação de calor. Em ambas as versões, utiliza muitos acessórios coloridos nos pulsos, como as tradicionais fitinhas de senhor do Bonfim. Seus movimentos de luta envolvem bastante contato físico e golpes de submissão como chaves de braço. Estes são executados de forma sorridente e algumas vezes extravagante, como quando alisa seus cabelos ou os joga para cima com movimentos amplos dos braços. Reforçada pelo rebolar e olhares que exibe nos movimentos de início e de vitória, esta linguagem corporal expressa a sensação de uma mulher sedutora, confiante e alegre. O uso recorrente de 
onomatopeias em suas falas completa a comunicação da personagem que privilegia a estética e o sensorial. A combinação destes elementos leva à conclusão de que Laura pode ser interpretada como um quali-signo icônico de sensualidade.

Certamente o verde, o amarelo e o azul encontrados nas vestimentas de Laura referem-se às cores convencionadas ao Brasil, através da bandeira nacional. Tal relação, apesar de já declarada de partida no jogo, é ainda mais reforçada por elementos como as pulseiras coloridas, que lembram as fitinhas de senhor do bonfim e miçangas, e as sandálias de praia, produto nacional exportado e bem reconhecido no exterior. Seus golpes estão associados ao judô e jiu-jitsu, este último referido no exterior também como brazilian jiujitsu. Quase todos os personagens de Street Fighter são capazes de utilizar algum tipo de energia elemental em combate, e neste aspecto Laura faz um tipo de auto referência ao utilizar poderes elétricos assim como Blanka, a imagem deste já convencionada ao Brasil no decorrer do tempo. Detalhes de seus movimentos como rebolar com as mãos no joelho e jogar os cabelos tombando a cabeça para o lado, remetem a uma dançarina de funk, e nos momentos em que abre os braços, lembra uma passista de carnaval. Apesar de não ser o foco desta análise, vale ressaltar que a personagem é vinculada a um cenário que lembra o Rio de Janeiro, com uma colorida favela ao fundo, uma montanha coroada com uma monumental Taça do Mundo FIFA, onde bem poderia estar o Cristo Redentor, e onde rainhas de bateria emplumadas dançam enquanto a luta ocorre. A justaposição de todos estes elementos simbólicos mostra que Laura representa um povo convidativo, mulheres belas e sensuais, onde calor e música são parte integrante da vida. Em Laura encontra-se um símbolo de Brasil País do Carnaval, alegre, festivo e turístico.

\section{A REPRESENTAÇÃO DO BRASIL E DO BRASILEIRO, EM TRÊS PLANOS.}

Esta análise dos personagens, posicionando-os ao longo do tempo, permite identificar mudanças na caracterização do Brasil e do Brasileiro, por parte da japonesa Capcom. Não se pretende descobrir ou descrever os motivos de tais mudanças, mas apenas refletir sobre as decisões no design dos personagens a partir do resultado observado. Serão interpretadas as características separando-as em três planos distintos: (1) o plano esportivo, (2) o plano da personalidade e (3) o plano do ambiente.

\subsection{Mudanças no plano esportivo.}


Percebe-se que no que concerne à modalidade de luta dos personagens houve uma maior definição e caracterização de seus estilos. Enquanto a maioria dos lutadores do título de 1991 utilizavam movimentos inspirados em algum tipo de luta como Karatê, Kung Fu, Sumô, Muay Thai e Boxe, Blanka lutava como uma fera, mordendo e arranhando seu oponente, sem traços de um treinamento formal ou estilo. Em Sean há estilo, porém, é o Shotokan do personagem Ryu, modificado pela inexperiência e personalidade do jovem. Por exemplo quando este atira sua bola de basquete no oponente. Entretanto a inserção da cabeçada e de outro movimento onde o personagem desfere socos no personagem caído, fazem alusão ao Vale-Tudo, estilo onde ficaram notórios brasileiros como Rickson Gracie, Vitor Belfort e Anderson Silva. Essa identificação se completa em Laura, que, através de suas falas e história no jogo, declara que luta o estilo "Matsuda jiu-jitsu." É interessante notar como a capoeira, estilo tradicionalmente associado ao Brasil, é deliberadamente evitado pelos desenvolvedores nos representantes do país. Há, no universo de Street Fighter, dois capoeiristas, o jamaicano Dee-Jay, e Elena, representante do Kenya. Contrariando o tradicionalismo nacional, o estilo de luta associado ao Brasil na série parece então tomar força nas artes marciais de submissão, como judô, jiu-jitsu e MMA.

\subsection{Mudanças no plano da personalidade.}

O brasileiro representado por Blanka, no início dos anos 90 era intimidador. É um ser que vive em um lugar primitivo, fruto da floresta, misterioso, incompreensível, fisicamente forte, mas intelectualmente subdesenvolvido. Se apresenta como uma figura exótica mesmo em relação aos outros personagens. Talvez uma visão oriunda da ainda pequena visibilidade internacional do país. Sean ainda carrega traços deste pouco desenvolvimento, mas na forma do jovem, do aprendiz, do iniciante. Neste personagem esta característica é redirecionada positivamente para a aspiração e a superação. Sean não está pronto, mas tem talento e dedicação e é confiante em seu progresso. De certa forma reflete assim algo do Brasil no final dos anos 90, como um país em desenvolvimento e uma promessa nos esportes. Por fim, Laura é a consolidação dessa confiança. Não em uma atitude de soberba ou arrogância, mas em uma atitude de segurança e autovalorização. Vaidosa, mas não necessariamente narcisista, é alegre e sensual. Postura de alguém que conquistou seu espaço e não sente vergonha em se mostrar. O brasileiro deixa de ser uma incógnita ameaçadora para se tornar uma diva expansiva. 


\subsection{Mudanças no plano do ambiente.}

O plano do ambiente insinua-se principalmente através dos cenários atribuídos a cada personagem. Percebe-se que estes ajudam muito a compor o personagem para o público. Segundo a história oficial da série, chancelada pela própria Capcom, Blanka estava em um avião que caiu na selva quando era uma criança e sobreviveu lutando contra predadores. No entanto, sua cor de pele esverdeada e golpes elétricos nunca são explicados. Blanka sempre é visto na floresta amazônica, e é esta relação que se estabelece primeiramente na mente do jogador. A primeira representação do Brasil na série, e quem sabe nos videogames, é o rio Amazonas, simbolizado pelo pirarucu, a sucuri e as casas de palafitas. O Brasil é reconhecido por sua natureza intocada, de grandes proporções e extensões, da qual Blanka parece ser um derivado. Em 1997, Sean é retratado nas ruas de uma cidade, que se afirma ser São Paulo, mas com poucos prédios altos, muitas palmeiras e macacos atacando um carregamento de bananas. Isso mostra que apesar de o foco geográfico ter se deslocado para o centro econômico do país, este não poderia ser representado sem sua natureza. Em edição posterior do mesmo jogo, Sean passa a ser retratado no porto de Santos, perto de navios de carga exportando café. Um símbolo mais ligado à pujança econômica do que às qualidades naturais. Finalmente Laura consolida a representação urbana do Brasil ao incorporar ao mesmo tempo a praia e a favela, e assim traços da cultura popular, em especial do sudeste brasileiro. Laura não aparece rodeada por macacos como seu irmão Sean, mas a natureza do Brasil ainda se encontra nos tucanos e nas frutas, assim como também estão presentes símbolos do carnaval e futebol. A representação faz então um movimento que parte de uma visão do nativo quase indígena, indo em direção a uma cultura mais urbana, de interesses e realidades variadas.

Tabela 3 - Comparativo entre os personagens

\begin{tabular}{llll}
\hline & \multicolumn{2}{l}{ Blanka } & \multicolumn{2}{l}{ Sean } & \multicolumn{2}{l}{ Laura } \\
\hline Ano de criação & 1991 & 1997 & 2015 \\
\hline Estilo de luta & Indefinido & Shotokan & Jiu-jitsu \\
\hline Personalidade & $\begin{array}{l}\text { Ameaçador, } \\
\text { misterioso }\end{array}$ & $\begin{array}{l}\text { Esforçado, } \\
\text { promissor }\end{array}$ & $\begin{array}{l}\text { Confiante, } \\
\text { Expansiva }\end{array}$ \\
\hline Ambiente & Floresta, selva & Cidade, urbanidade & Favela, praia \\
\hline $\begin{array}{l}\text { Quali-signo icônico } \\
\text { de }\end{array}$ & Monstruosidade & Juventude & \multicolumn{2}{|l}{ Sensualidade } \\
\hline
\end{tabular}




\section{CONSIDERAÇÕES FINAIS}

A partir das análises, pode-se construir um panorama geral que ajuda a identificar o conjunto de mensagens transmitidas pelos personagens ao público. Para o brasileiro dos anos 90 que desejava se ver representado ou encarnar em uma manifestação virtual que representasse seus valores e modo de vida, a opção por Blanka talvez fosse indigesta. Um monstro da floresta talvez não fosse a primeira autoimagem que o jogador teria, mas a história mostra que este encontrou seu espaço. Talvez até pelo absurdo e exclusividade de sua aparência, ou pela possível identificação com criaturas folclóricas como o Curupira e seus cabelos de fogo, o fato é que este personagem conseguiu a simpatia do público e ganhou seu espaço na série e na aceitação popular, estando entre os personagens que mais apareceram nos jogos e outros produtos da franquia. O mesmo não parece ter acontecido com Sean, a julgar pela falta de aparições deste em papéis de destaque na franquia nos últimos 20 anos. Apesar de o público brasileiro ter sido contemplado com um lutador humano, cujas características estão próximas dos principais protagonistas da série, este parece ter sido construído sem ligações reais com o país em questão. Nesse sentido, o monstro descalço é mais carismático e reflete mais elementos do imaginário popular nacional do que o garoto jogador de basquete. Nas décadas seguintes, entretanto, o cenário dos jogos digitais mudou com a demanda por mais jogos online como os MMORPGs e a demanda por customização e representatividade. Talvez por isso a personagem Laura traga muito mais elementos brasileiros do que seus antecessores. A carioca extrovertida, por mais hiperssexualizada que seja, ainda reflete mais temas familiares aos brasileiros, independentemente de sua região.

Com certeza uma representação fiel do que seria um "brasileiro" não é possível, visto que identidades nacionais são muito difíceis de se padronizar, em especial em um país de proporções continentais. Ao mesmo tempo em que um morador do sudeste brasileiro pode perceber traços da sua realidade e contexto em Laura, um gaúcho ou um paraense talvez 
sintam falta de suas tradições locais. Assim como é possível entender que Laura manifesta uma atitude auto afirmativa de empoderamento através de sua sensualidade, é possível enxergar nestas mesmas características um estereótipo vulgar. Portanto não se trata de afirmar aqui que determinada representação é de fato melhor que a outra, mas sim que há no decorrer dos lançamentos da série uma complexificação saudável da representação do brasileiro. De um personagem altamente caricato que se liga ao brasil por uma vaga ideia romântica de natureza selvagem, tropeçamos em um personagem que se liga fracamente ao Brasil apenas por seu biotipo e uma convenção sobre sua origem, para então chegarmos a uma personagem que comporta tanto elementos de biotipo quanto elementos de cultura que podem ser mais facilmente identificados por jogadoras e jogadores brasileiros.

\section{REFERÊNCIAS}

ALMEIDA, C. S.; PEREIRA, L. B.; NÓBREGA, T.; PEREZ, C. Personagem de Marca: Análise Semiótica da Moça Leiteira. XXXII Congresso Brasileiro de Ciências da Comunicação. Curitiba, PR. 2009

BARROCO, S.M.S.; SUPERTI, T. Vigotski e o estudo da psicologia da arte: contribuições para o desenvolvimento humano. Psicologia \& Sociedade, Vol 26(1), 22-31. 2014.

BAUMAN, Z.; VECCHI, B. Identidade. Entrevista a Benedetto Vechhi. Tradução Carlos Alberto Medeiros. Rio de Janeiro: Zahar. 2005.

CAPCOM. Game Series Sales. 31/12/2016. Disponível em:

<http://www.capcom.co.jp/ir/english/finance/salesdata.html>. Acesso em 20/02/2017.

. Street Fighter [Video Game]. [S.1]: Capcom Co., Ltd. 1985. Arcade.

. Street Fighter II: The World Warrior [Video Game]. [S.1]: Capcom Co., Ltd. 1991. Arcade.

. Street Fighter III [Video Game]. [S.1]: Capcom Co., Ltd. 1997. Arcade.

. Street Fighter V [Video Game]. [S.1]: Capcom Co., Ltd. 1997. Digital, Disco [Linux, Microsoft Windows, Playstation 4.]

DICKEY, M. Game design and learning: a conjectural analysis of how massively multiple online role-playing games (MMORPGs) foster intrinsic motivation. Educational Technology Research and Development, Vol 55(3), 253-273. 2007

NAUGTHY DOG. The Last of Us [Video Game]. [S.1]: Sony Computer Entertainment, 2013. Digital, Disco [Playstation 3, Playstation 4]

EAGLETON, T. A Ideia de Cultura. Tradução Sandra Castello Branco. São Paulo: Editora UNESP. 2015.

EL-NASR, M. S.; BISHKO, L.; ZAMMITTO, V. NIXON, M. WEI, H.; ATHANASIOS, V. Believable characters. In Borko Furht (Editores). Handbook of Digital Media in Entertainment and Arts. (SCI), Chapter 22. 2009 
BLIZZARD ENTERTAINMENT. Overwatch [Video game]. [S.1]: Blizzard Entertainment, 2016. Digital, Disco [Microsoft Windows, Playstation 4, Xbox One]

World of Warcraft [Video game]. [S.1]: Blizzard Entertainment, 2016. Digital, Disco [Microsoft Windows, Mac OS X]

FRANCISCO, T.; GARONE, P. M. C. Design de Personagens e Representação Gráfica: Uma Construção Semiótica. Graphica 13, XXI Simpósio Nacional de Geometria Descritiva e Desenho Técnico. Florianópolis, SC. 2013.

FROSI, F. O.; STEFFEN, C. Direcionamentos no Character Design: uma análise arquetípica e semiótica dos personagens de jogos digitais. XIV Simpósio Brasileiro de Games. Teresina, PI. 2015.

RIOT GAMES. League of Legends [Video Game]. [S.1]: Riot Games, 2009. Digital [Microsoft Windows, MAC OS X]

GÜNTZEL, E.; TASSOTTI, M. V. B.; SANTOR, F. Analise Comparativa: Homem-Aranha x Batman. XII Congresso de Ciências da Comunicação na Região Sul. Londrina, PR. 2011.

HEFNER, D.; KLIMMT, C.; VORDERER, P. Identification with the Player Character as Determinant of Video Game Enjoyment. In L. Ma, R. Nakatsu, and M. Rauterberg (Editores): The International Conference on Electronic Commerce, LNCS 4740, pp. 39-48, 2007.

KRESS, G. Multimodality: A Social Semiotic Approach to Contemporary Communication. London:Routledge. 2010.

MAAGERØ, E.; ØSTBYE, G. L. What a Girl! Fighting Gentleness in the Picture Book World: An Analysis of the Norwegian Picture Book What a Girl! by Gro Dahle and Svein Nyhus. Children's Literature in Education. 2016. DOI: 10.1007/s10583-016-9276-4

MAFFESOLI, M. Tribalismo pós-moderno: da identidade às identificações. Folmann, J. (Trad.) Ciências Sociais Unisinos, Vol 43(1), 97-102. 2007.

MIDWAY MANUFACTURING CO. Ms. Pac-Man [Video Game]. [S.1]: Midway Manufacturing Co. 1981. Arcade.

MCWHERTOR, M. Blizzard wants its diverse fans to feel 'equally represented' by Overwatch's heroes. Polygon. 08/11/2014. Disponível em: <http://www.polygon.com/2014/11/8/7176861/blizzardoverwatch-diversity>. Acesso em 20/02/2017.

NINTENDO, E. A. D. Super Mario Bros. [Video Game]. [S.1]: Nintendo Co. Ltd.1985. Cartucho [Nintendo Entertainment System]

REDBULL. Episódio 1 : Arcades Improvisados. Paralelos. Redbull. 09/11/2016. Documentário online. Duração 6min 39s. Disponível em:

<http://www.redbull.com/br/pt/games/episodes/1331828460425/paralelos-epis\%C3\%B3dio-1arcades-improvisados> Acesso em 20/02/2017.

SANTAELLA, L. Semiótica aplicada. São Paulo: Cengage Learning, 2002.

. A Teoria Geral dos Signos: Semiose e Autogeração. São Paulo: Editora Ática S.A., 1995.

Leitura de Imagens: (Como Eu Ensino). São Paulo: Editora Melhoramentos, 2012.

SQUIRE. K. Video Games in Education. International Journal of Intelligent Games \& Simulation, Vol 2 (1). 2003. 
ULICSAK, M.; CRANMER, S. Gaming in Families: final report. Futurelab, 2010.

WALLBRIDGE, M. In-Depth: Inside The EVO 2009 Fighting Game Championships. Gamasutra. 22/07/2009. Disponível em: <http://www.gamasutra.com/php-bin/news_index.php?story=24520> Acesso em 20/02/2017.

Original recebido em: 31 de março de 2017

Aceito para publicação em: 17 de junho de 2019

Rafael Arrivabene

Mestre em Engenharia e Gestão do Conhecimento pela Universidade Federal de Santa Catarina, e atualmente doutorando no mesmo programa. É game designer e professor do curso de Design de Jogos e Entretenimento Digital da Universidade do Vale do Itajaí. Pesquisa o papel dos jogos na disseminação do conhecimento e aplicações diversas da atividade de game design, para além do entretenimento.

\section{José Roberto Cordeiro}

Bacharel em Design pela UFSC. Mestrando do Programa de Pós-Graduação em Engenharia e Gestão do Conhecimento da Universidade Federal de Santa Catarina. Pós-Graduando em Design Instrucional no Senac EAD.

Rafael Arrivabene

Professor dos cursos de graduação, mestrado e doutorado em Design (Pós-Design) e do Programa de Engenharia e Gestão do Conhecimento (PPEGC) da Universidade Federal de Santa Catarina, com formação e Artes Visuais, mestrado em Educação (UFMS, 2005) e doutoramento em Comunicação e Semiótica (PUC/SP, 2001). Realizou estágio sênior pós-doutoral em Design (IADE, Lisboa, 2015) e é

o líder do grupo de pesquisa "Significação da Marca, Informação e Comunicação Organizacional"

(SIGMO/UFSC/CNPq).

\section{@ $\odot \otimes 0$}

Esta obra está licenciado com uma Licença

Creative Commons Atribuição-NãoComercial-CompartilhaIgual 4.0 Internacional 